Iraq

2 The Bush Administration Begins to Build its Case for War Against Iraq

\title{
World Summit on Sustainable Development
}

88 Summit on Sustainable Development

Stresses the Importance of Public-Private Partnerships;

Bush Declines to Attend, Sends Powell

\section{Archive: Climate Change Policy}

109 Bush Decision to Withdraw from the Kyoto Protocol Creates Rift With Europe

\section{The "War on Terrorism"}

154 Campaign in Afghanistan Moves into the Background;

U.S. Commemorates One Year Anniversary of the

September 11 Attacks

187 List of Documents

190 Index 